\title{
Research on the Accounting Information of Small and Micro Enterprises
}

\author{
Yi Sun \\ Liaoning Economic Vocational Technology Institute, Liaoning Shenyang, 110122 \\ mazda525@126.com
}

\begin{abstract}
This paper analyzes the status of small and micro enterprises in the construction of accounting information. Many small and micro enterprises still remain in the accounting stage of accounting computerization and even manual accounts, and the construction of accounting information is faced with many difficulties. This paper studies the common problems of financial management in different type's small and medium-sized enterprises, and puts forward the improvement scheme for these problems, and analyses the financial needs of small and micro enterprises, and puts forward the design and construction scheme.
\end{abstract}

Keywords: Small and micro enterprises; Accounting information; Enterprise financial management.

\section{Introduction}

With the rapid development of science and technology, information technology has begun to fully infiltrate all aspects of enterprise management, and the application of information has important practical significance for small and micro enterprises. Accounting information is the combination of accounting and information technology. It means that information technology is widely used in accounting work, information resources are developed, accounting information is used as management information resource, and computer, network communication and other information technology are used to obtain, process, transmit and apply. Control cost and economic operation provide real-time and omnidirectional information. Accounting informatization has always been the core of enterprise informatization and an important part of the informatization of small and micro enterprises.

\section{The problem of accounting information faced by small and micro enterprises}

The survival of small and micro enterprises is still very difficult. The accounting information construction of small and micro enterprises in China is still at a low level, and there are the following main problems.

\subsection{Enterprises' lack of understanding for accounting information}

Inevitably, there will be various misunderstandings in the construction of accounting informatization. Small and micro enterprises are affected by their own scale and the nature of enterprises, the education level and managers thought is limited, the managers do not want to use modern information system to assist the management of enterprises At present, many small and micro enterprises still have accounting management in the stage of hand keeping. In the enterprises that carry out the accounting information, many enterprises equate accounting information with accounting computerization, only simply use the accounting information software to deal with the basic accounting business, such as voucher filling, book compilation, and generating reports, and cannot establish a complete accounting information system.

\subsection{The foundation of accounting informationization is weak}

After years of development, the conditions for comprehensively promoting accounting informatization in China are basically mature. However, the foundation of accounting information in small and micro enterprises is still relatively weak. First, most of the small and micro enterprises are affected by various factors, and their management level and management system remain at a low level. There are still problems in small and micro enterprises, such as extensive management, low management level, irrational organizational structure, and decision mechanism to be improved. Secondly, small and micro enterprises have problems of financing difficulties and unreasonable capital structure, which are relatively small, low survival rate, and cannot get strong financial support, so that the funds which can invest in the 
construction of accounting information are quite limited. Lack of funds is a major obstacle to information construction in small and micro enterprises.

\subsection{Enterprises are faced with weak technological strength and complex talent shortage.}

Accounting information construction is a very systematic and comprehensive work. To make this work well, enterprises need to master the information technology of modern electronic technology, network technology and accounting information technology. At the same time, the quality of accountants and managers should be higher. At present, most of our small and micro enterprises have no advanced management means, the understanding of financial software is not comprehensive enough, and many small and micro enterprises even lack the standard internal computer network. The small and micro enterprises are mostly private enterprises. The traditional employment concept in our country leads to the technical talents not willing to get to the small and micro enterprises, and due to the cost considerations, the small and micro enterprises are reluctant to employ the compound talents, which leads to the lack of the complex talents, which are necessary to understand the technology and understand the management of the accounting information construction, which directly affect the process of accounting information in small and micro enterprises.

\subsection{The social service system is not sound}

Informatization is a complex process, which needs to be fully realized on the basis of the whole social service system. However, the overall starting point of enterprise informatization in China is low, and infrastructure and information exchange are still weak. In view of the fact that the social service system of small and micro enterprises is not perfect, it is difficult to get timely and accurate market information for small and micro enterprises. In addition, small and micro enterprises information consulting institutions and enterprises engaged in enterprise information engineering supervision are few, resulting in the quality of the small and micro enterprises accounting information projects cannot be guaranteed. The government departments have not paid enough attention to the accounting information of small and micro enterprises. It has not made a unified planning of accounting information for small and micro enterprises, and lacks relevant standards and standards.

\section{Design and implementation of financial information system in small and micro enterprises}

\subsection{User background and requirement analysis}

The financial information system of small and micro enterprises mainly includes the following nine modules: system management setting module, procurement management module, sales management module, production management module, inventory management module, asset management module, salary management module, general ledger module, and cash bank deposit module. The relationship between these modules is shown in Figure 1.

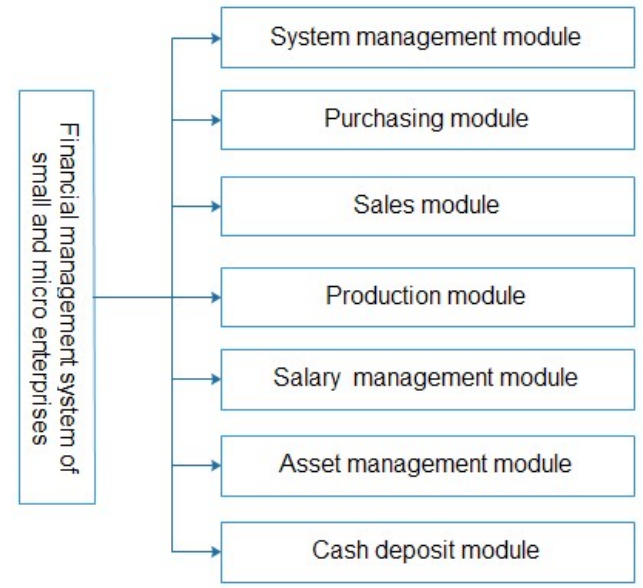

Figure 1. Design diagram of financial information system module.

\subsection{Analysis of accounting process}

The general process of accounting treatment is input from the voucher. First, each business is input into the system, then the voucher is audited. We can show this process with a diagram. The accounting process of general accounting computerization is shown in Figure 2 below.

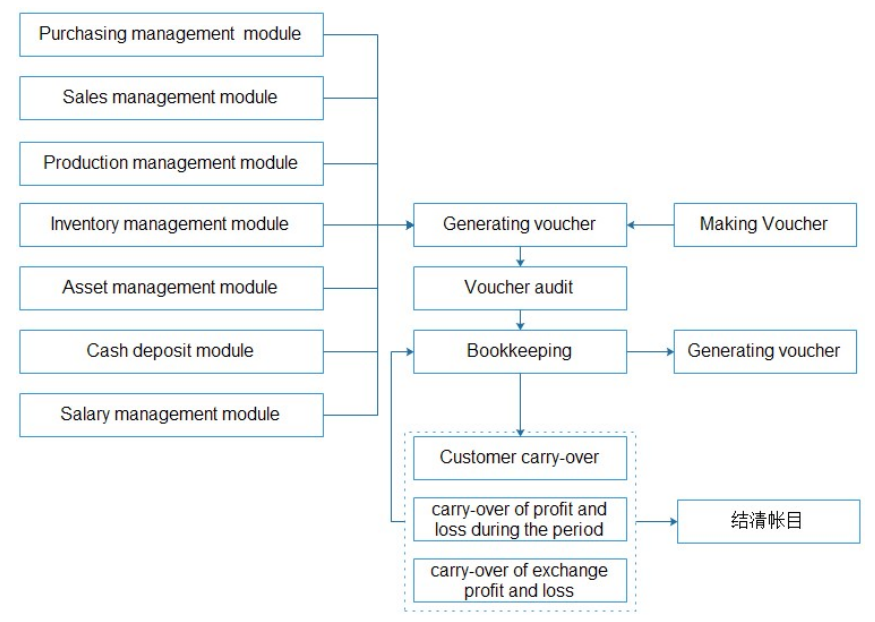

Figure 2. Flow chart of accounting treatment.

\section{Suggestions on promoting the accounting information of small and micro enterprises}

Under the background of the full implementation of information technology in the country, small and micro enterprises should comply with the trend of modern enterprise management information technology, make full use of modern information technology, such as computer 
and Internet, and do a good job of enterprise accounting information.

\subsection{Perfecting the basic work of accounting information}

Accounting informatization is the basis of accounting information for small and micro enterprises, as well as the starting point of accounting informatization. The basic accounting work includes the original materials records of purchase, consumption and the production sale. It objectively and truthfully records the whole process of enterprise logistics, capital flow, and the requirements of the allocation and management of human resources. Therefore, on the basis of the optimization of business process, it is necessary to provide comprehensive accounting information through the accounting information system to effectively serve all levels of personnel in time, and the optimized business flow chart is illustrated as shown in Figure 3.

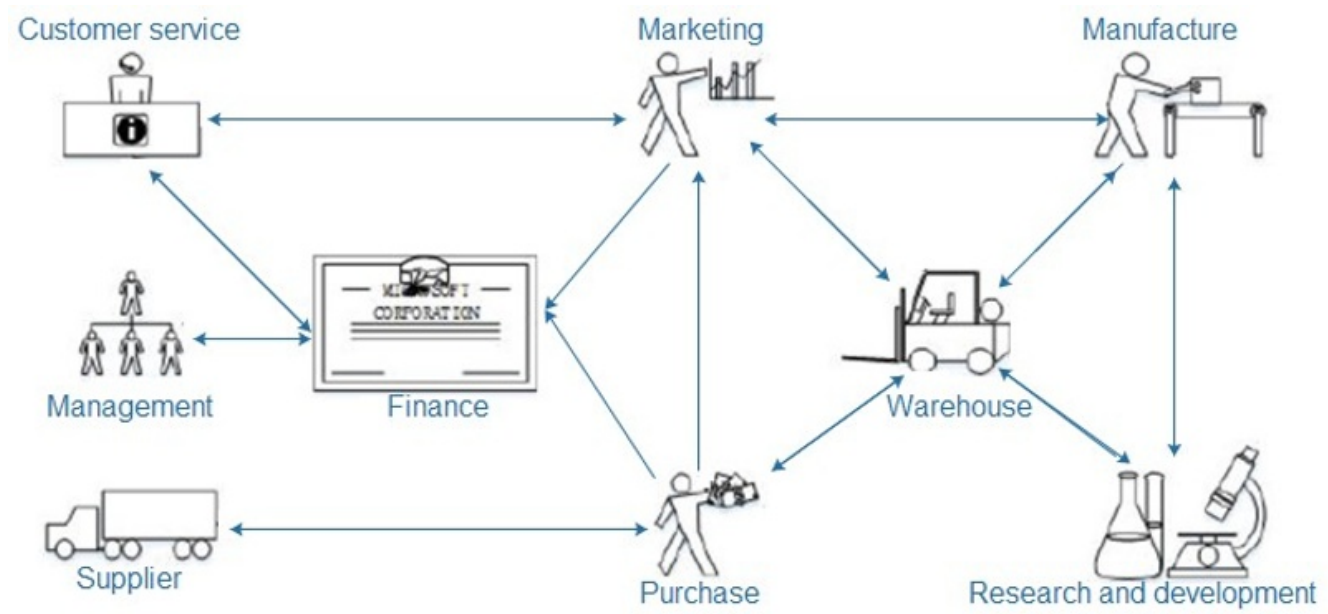

Figure 3. Optimized business processes.

\subsection{Strengthening enterprise's basic management and internal control}

Accounting function under accounting information environment is characterized by participation in management and auxiliary decision-making. Therefore, before the construction of accounting informatization, small and micro enterprises must establish a sound internal management and control system, standardize the management and control system of business process, post establishment and authority management under the environment of accounting informationization. First, it is necessary to create an environment suitable for accounting informationization so as to adapt the information communication and supervision to the information requirements of internal control. The two is to adjust and transform the internal control of responsibility structure, business structure and organization structure by using the information technology, combining the business process, the information degree and the personnel quality. The three is to define the accounting job post and the corresponding post responsibility system according to the information processing degree.

\subsection{Absorbing compound talents to the employment in small and micro enterprises}

On the one hand, the government should change the traditional employment concept by improving the employment policy and strengthening the employment guidance, so as to attract the accounting information personnel to the small and micro enterprises. On the other hand, small and micro enterprises should start from their own actual conditions, improve the employment treatment of skilled personnel, and actively attract information talents At the same time, enterprises need to carry out information education and training for employees, including modern information technology, accounting knowledge and management theory, and improve the comprehensive quality and ability of the accountants.

\subsection{Give full play to the functions of government}

The government should play a certain regulatory function, do well in organization and coordination, provide policy guidance for small and micro enterprises to carry out accounting information construction, perfect the relevant rules and regulations and standards system of accounting information, clear the objectives and technical standards of the construction of small and micro enterprises information, and smoothly guide small and micro enterprises to carry out information construction work. The government departments should also do a good job of publicity and promotion, create a good environment for accounting information, and transform the government's strategic intention into the subjective will of the unit and individual.

\section{Conclusions}

It is a long process to realize accounting informatization in 
an all-round way. The accounting informationization of small and micro enterprises is still facing many difficulties. It is a arduous task to realize the comprehensive accounting information for small and micro enterprises. However, comprehensively promoting the work of accounting information is the established goal of China's accounting information development strategy, and it must be carried out unswervingly. We should steadily promote the development strategy of accounting information in small and micro enterprises, improve the level of accounting management and work efficiency of small and micro enterprises in an all-round way, and improve the economic development level of small and micro enterprises.

\section{References}

1. Zhang Guili. Influence of Accounting Informationization on enterprise financial management and Countermeasures [J/OL]. China Business \& Trade, 2017, 10 (21): 81-82.

2. An Hong. Analysis of the development of financial accounting in the era of network economy [J]. Economic Research Guide. 2017,11 (20): 124-125.

3. Xue Yao. The influence and Countermeasures of enterprise financial management under the background of Accounting Informationization [J]. Modern Economic Information. 2015, 12 (11): 153.

4. Gao Ming, Wu Yuanzheng. Research on the evaluation and promotion of financial informatization construction of Jiangsu's small and medium sized enterprises [J]. Jiangsu Commercial Forum. 2013, 23 (05): 53-56.

5. Wang Hui. The influence of Accounting Informationization on modern enterprise financial management and its construction [J]. Science and Technology Innovation Herald. 2010, 10 (34): 200. 